\title{
THE DETERMINANTS OF CHANGES IN THE ORGANISATION OF PRODUCTION: EVIDENCE FROM SPANISH PLANT-LEVEL DATA
}

\author{
Alberto Bayo \\ José Enrique Galdón-Sánchez
}

Ricard Gil 
The Public-Private Center is a Research Center based at IESE Business School. Its mission is to develop research that analyses the relationships between the private and public sectors primarily in the following areas: regulation and competition, innovation, regional economy and industrial politics and health economics.

Research results are disseminated through publications, conferences and colloquia. These activities are aimed to foster cooperation between the private sector and public administrations, as well as the exchange of ideas and initiatives.

The sponsors of the SP-SP Center are the following:

- Accenture

- Ajuntament de Barcelona

- Caixa Manresa

- Cambra Oficial de Comerç, Indústria i Navegació de Barcelona

- Consell de l'Audiovisual de Catalunya

- Departamento de Economía y Finanzas de la Generalitat de Catalunya

- Departamento de Innovación, Universidades y Empresa de la Generalitat de Catalunya

- Diputació de Barcelona

- Fundació AGBAR

- Garrigues

- Mediapro

- Microsoft

- Sanofi Aventis

- VidaCaixa

The contents of this publication reflect the conclusions and findings of the individual authors, and not the opinions of the Center's sponsors. 


\title{
THE DETERMINANTS OF CHANGES IN THE ORGANISATION OF PRODUCTION: EVIDENCE FROM SPANISH PLANT-LEVEL DATA
}

\author{
Alberto Bayo ${ }^{1}$ \\ José Enrique Galdón-Sánchez ${ }^{1}$ \\ Ricard Gil ${ }^{2}$
}

\begin{abstract}
In this paper we empirically examine the determinants of changes in the organization of production using detailed information on a data set from a new plant-level survey from 1003 plants distributed in all manufacturing industries in Spain. In particular, and among many other things, survey respondents are asked how practices of outsourcing of services to others had changed in the last three years. The answer to this question is informative of the changes in the importance of backward integration for each of the plants interviewed. Using other information provided in the survey, we relate the reported changes in outsourcing to changes in other relevant dimensions as possible determinants of the boundaries of the firm. These are plant size, downstream market power, cost of inputs, price and quality of the final good and technological progress. Our findings show that outsourcing increases are strongly positively correlated with increases in market quota and increases in market competition. We also find that outsourcing increases when plants face simultaneous increases in product quality and product prices, and that outsourcing decreases when plants face simultaneous increases in market quota and market competition. Finally, we find that multi-plant and one-plant firms adjust their outsourcing practices differently to outside changes. Since either TCE or PRT theories of vertical integration fail to fully explain the patterns found in our data, we close this paper by following Adam Smith's claim that the extent of the market seems to be the only factor consistently limiting the degree of specialization in our setting.
\end{abstract}

Classification JEL: L23, L22, L60

Keywords: outsourcing, vertical integration, competition, manufacturing plants.

\footnotetext{
${ }^{1}$ Universidad Pública de Navarra

${ }^{2}$ UC-Santa Cruz
} 


\section{THE DETERMINANTS OF CHANGES IN THE ORGANISATION OF PRODUCTION: EVIDENCE FROM SPANISH PLANT-LEVEL DATA}

\section{Introduction}

Mere observation and anecdotal evidence over the years have shown that firms and organizations display a wide variety of ways to organize the production of their different products or even of a same item. This fact remains a puzzle for economists since most theoretical approaches cannot explain different organizational forms taking place in the same industry (see Grossman and Helpman, 2002, among others ${ }^{2}$ ). Therefore, understanding the organization of production within and across industries as well as within and across firms' boundaries is important for the study of economics in general.

The study of the organization of production owes its beginnings to Coase (1937). Coase's contribution remains the first to post the question of why firms organize their production in the way they do; mainly on how firms reach their make-or-buy decisions. Alchian and Demsetz (1972) followed up Coase's analysis and shed light on the importance of information coordination for production. Not much later, Williamson (1975 and 1979), Klein, Crawford and Alchian (1978) and Grossman and Hart (1986) started vertical integration theories of Transaction Cost Economics (the former two) and Property Rights Theories (the latter).

Despite all these theories, evidence on how production organization takes place within and across firms has been scarce. ${ }^{3}$ Even though early papers by Masten (1984) and Monteverde and Teece (1982) seem to support predictions of Transaction Cost Economics theories, these and other more recent papers say little about Property Rights Theories (see Whinston, 2003). This clearly means that there is yet a long way to go in understanding how different theories and

\footnotetext{
${ }^{1}$ We would like to thank Sara Martínez de Moretín for valuable research assistance. We thank the Fundación BBVA for providing us with funding to conduct the survey in the Spanish establishments. The first and second authors acknowledge financial support from Ministerio de Educación y Ciencia project SEJ2007-66511 and Ministerio de Ciencia e Innovación project EC02008-02641.

${ }^{2}$ Legros and Newman (2008) is an exception where, under certain circumstances, different organizational forms coincide in an industry.

${ }^{3}$ Some recent empirical evidence from the vertical integration literature not cited throughout the paper are Forbes and Lederman (2008), Gil (2008) or Gil and Hartmann (2008). See Lafontaine and Slade (2008) for an extensive literature review.
} 
the different organizational trade-offs posted by these theories are relevant for the final understanding of the patterns that we observe in the real world.

Our paper here presents additional evidence on how firms organize their production and, furthermore, how firms change the organization of their production when they experience changes in their competitive environment. Therefore our contribution is mainly on the empirical side and, if anything, we hope our results will foster further theoretical research that may provide sound explanations for the patterns in outsourcing that we find in our data set.

For this reason, we present a new data set on manufacturing plants in Spain. This unique data set comprises direct information on several firm's practices for 1003 industrial establishments in Spain. The data set has its origin on a survey conducted in 2006. All surveyed establishments are involved in production processes within the manufacturing sector. The questionnaire consists of 152 questions grouped in eight sections, and some of these questions provide valuable information regarding vertical integration and outsourcing practices. Overall, we obtain very homogeneous data for every surveyed plant. At the same time, the survey contains a wide scope of different firms within the manufacturing sector.

Since those variables of interest in this data set and relevant to our study are informing us of changes occurred in outsourcing practices within a plant (as well as changes in other plant dimensions) in the last three years, we take these as proxies for first differences of the relevant variables and we proceed to regress first differences of our dependent variable on first differences of our explanatory variables. Following this procedure we guarantee that the error terms in these regressions are clean of any time-invariant plant-level characteristic that may be correlated with any of the explanatory variables and may bias results from the levels regressions.

Our main findings show that, once we hold constant sector-level shocks as well as changes in all relevant explanatory variables, only increases in competition and increases in the plant's market quota are positively correlated with increases in outsourcing. We also find that plants that see a simultaneous increase in both competition and market quota decrease outsourcing practices. Finally, we find evidence that plants that simultaneously face increases in product quality and product prices are also more likely to increase outsourcing.

We investigate further the robustness of these results and consider whether plants belonging to one-plant firms and plants belonging to multi-plant firms react differently to the changes in our explanatory variables. We find that these two types behave differently and therefore our main findings are the result of a composition effect. In particular, we find that one-plant firms only increase outsourcing when they experience an increase in market quota and when they face a simultaneous increase in product quality and product prices. On the other hand, plants belonging to multi-plant firms increase outsourcing when they experience an increase in competition and they decrease outsourcing when they face a simultaneous increase in competition and market quota. This difference in behavior also informs us that firms that are constrained in the way they can reorganize production. Oneplant firms are less likely to change their internal organization of production when facing changes in competition, but they are more likely to increase outsourcing when facing increases in market quota. On the other hand, multi-plant firms can reorganize production across their multiple plants and will be more likely to adjust the organization of their production when facing changes in market competition and not as likely when experiencing changes in their plant's market quota. 
Finally, despite the use of variables in differences in our analysis and the inclusion of industry and sector fixed effects, we are concerned there may still be problems of variable omission and endogeneity. For this reason, we include other regressors that may be correlated with the error term in ways that our main specifications are not capturing. Our results are robust to this final robustness check.

The paper is organized as follows. After this introduction, we extensively describe our data set and the variables relevant for our study in section 2. Section 3 presents our methodology. Next, we show our results and the robustness checks that we undertake in section 4. In this section, we also offer a discussion of how our findings relate to and validate previous results in the empirical make-or-buy literature. Section 5 concludes.

\section{Data Description}

In this section we describe the data source, how the data were collected and the variables that we use in our empirical exercise. We will start by describing the questionnaire from which we obtained the data set and then proceed to describe the variables used in our analysis.

\section{The questionnaire}

Our analysis is based on data from a Spanish data set collected in 2006 as part of a survey on firms' practices in the Spanish manufacturing industry. The data was gathered through personal interviews with managers in manufacturing plants with fifty or more employees, and represents a unique source of information about diverse practices in Spanish firms. The project was intended to be a partial continuation of a previous study on HRM and operations management carried out in 1997. Information was collected at the plant level; the unit at which decisions about the implementation of the practices of interest are taken. Furthermore, the knowledge of the issues included in the questionnaire is expected to be greater at plant level and, as a consequence, the data obtained should be more reliable.

Once the objectives and scope of our study was defined, and in order to properly design the questionnaire, we carried out a thorough examination of the literature related to the purpose of the project. With the information gathered, a first draft of the questionnaire was drawn up jointly by the members of the research group and the company in charge of the fieldwork. The questionnaire was pre-tested in nine plants and then modified in several ways to come up with its final version.

This final version of the questionnaire consists of 152 questions grouped in the following eight sections: General Characteristics of the Plant and the Firm, Human Resources, Payment Systems, Work Organization, Human Resource Outcomes, Human Resource Function, Other Groups of Workers and Characteristics of the Plant Manager. Most of the information on HRM refers exclusively to blue-collar workers; that is, those workers involved directly in the production process. The reason for restricting the analysis to this category of employees lies in the existence of diverse internal labor markets with different features within the same organization. Limiting the study to manual workers facilitates comparisons across establishments. 
The data was drawn from personal interviews with one of the managers at the plant. At first, it was thought that questions should be addressed to the general manager or to the human resource manager. Finally, it was decided that any manager at the plant was qualified to complete the questionnaire, although the human resource manager was the most frequently interviewed.

The universe of potential respondents for the purposes of the project was constituted for all Spanish manufacturing establishments with fifty or more employees in 2005, which amounts to 6971 units. The aim was to obtain a sample of one thousand units, in order to reach conclusions that could be extrapolated to the entire Spanish manufacturing industry. After stratification by sector, size and location, a random selection of workplaces was obtained from the 2005 Spanish Central Directory of Firms (Directorio Central de Empresas, DIRCE) of the Spanish National Statistics Institute (Instituto Nacional de Estadística, INE).

The interviews with those managers that agreed to answer our questionnaire were performed by specially-trained professionals using computer assisted telephone interviews (CATI). The establishments were first approached by a letter or an email indicating the goals of the survey and including a copy of the questionnaire.

\section{The variables}

In what follows, we describe the variables used in our empirical analysis. The sample means, standard deviations and definitions of these variables are presented in Table 1.

\section{Table 1}

Summary Statistics

\begin{tabular}{lccccc}
\hline Variable & Obs & Mean & Std. Dev. & Min & Max \\
Change in outsourcing? & 926 & 0.27 & 0.65 & -1 & 1 \\
Change in \# employees? & 1001 & 0.16 & 0.82 & -1 & 1 \\
Change in production costs? & 988 & 0.67 & 0.49 & -1 & 1 \\
Change in product quality? & 962 & 0.55 & 0.72 & -1 & 1 \\
Change in product price? & 964 & 0.47 & 0.69 & -1 & 1 \\
Change in competition? & 971 & 0.59 & 0.55 & -1 & 1 \\
Change in market quota? & 891 & 0.38 & 0.67 & -1 & 1 \\
Average \# employees 2005 & 1001 & 188.01 & 467.87 & 21 & 12810 \\
First year of plant & 979 & 1969.11 & 29.37 & 1700 & 2006 \\
Multi-Plant Firm? & 1003 & 0.47 & 0.50 & 0 & 1 \\
Percentage Labor Cost & 756 & 31.67 & 17.22 & 1 & 90 \\
Change in technology? & 1003 & 0.62 & 0.49 & 0 & 1 \\
\hline
\end{tabular}

This table provides summary statistics of all variables used in our empirical section. 
The Spanish questionnaire provides information on the factors that influence outsourcing practices and vertical integration. The information regarding those factors is obtained from the answers given in the questionnaire to a block question. In that question, the establishments are asked about the evolution of several aspects related to the plant in the three years prior to the survey. The seven aspects considered are the following: the change in the outsourcing carried out by the plant (change in outsourcing), the change in the number of employees at the plant (change in \# employees), the change in the plant's production cost (change in production cost), the change in the plant's product quality (change in product quality), the change in the plant's product price (change in product price), the change in the sector's competition of the plant (change in competition) and the change in the market quota of the plant (change in market quota). For each of these questions, the establishments were given five different options ranging from a large reduction (1) to a large increase (5) in the aspect being evaluated. We have recoded these answers assigning value 1 if there is an increase (values 5 and 4 in the original answer), value 0 if there is no change (value 3 in the original answer) and value -1 if there is a decrease (values 1 and 2 in the original answer). We used this criterion mainly because most observations in the original answer took values 2, 3 and 4 and, therefore, relying only on the extreme values 1 and 5 would have left us with almost no variation.

Along with these core variables, there are some others that we have used as controls in our empirical analysis. We can classify them in two groups depending on the type of question that was used to create the variable: questions that required a quantitative answer from the interviewee and questions that elicited a qualitative answer. Among the first group we have the percentage represented by the labor costs in the total production cost of the establishment (percentage labor cost), the year in which the plant was built (first year of the plant), the average number of employees that the plant had in the year 2005 (average \# employees 2005) and a dummy variable that takes value zero if the plant belongs to a single-plant firm and value one if it belongs to a multi-plant firm (multi plant firm). Among the second group we have only one variable (change in technology). In our survey, the establishments are asked about the technical change implemented by the plant in the three years previous to the survey (if any). To answer that question, they were given five different options ranging from a total change to no change at all. From the answers gathered to that question we construct our variable in the following way: we assign value 1 if there has been substantial change in technology (values 5 and 4 in the original answer), value 0 if there has been no change (value 3 in the original answer) and value -1 if there has been little or no change at all (values 1 and 2 in the original answer).

Finally, the sector composition of our sample of plants appears in Table 2. We will use this in our empirical exercise to obtain the industry fixed effects and the industry-sector fixed effects. We define an industry as firms involved in the production of similar products, and sectors within an industry as those involved in production of items sold to a similar range of customers. For example, all firms involved in the production of textile products comrpise the textile industry. In addition to this, we may divide these firms in three sectors within this industry; those that produce capital goods used in textile production, those that produce intermediate goods that are bought by other firms in this and other industries, and those that produce textile products for final consumers. In our sample, some of the plants appear in more than one industry and sector. 


\section{Table 2}

Sector composition of our sample

\begin{tabular}{lcccc}
\hline Variable & Capital & Intermediate & Consumption & Total \\
Food, Beverages and Tobacco & 0 & 8 & 148 & 156 \\
Textile & 4 & 16 & 48 & 69 \\
Wood and cork & 2 & 18 & 13 & 34 \\
Paper and Graphical Arts & 4 & 24 & 41 & 70 \\
Chemical industry & 4 & 31 & 48 & 81 \\
Plastics & 20 & 26 & 22 & 68 \\
Mineral products no metals & 16 & 50 & 41 & 108 \\
Metalic Products & 55 & 66 & 33 & 154 \\
Mechanical equipment & 53 & 9 & 11 & 75 \\
Electrical equipment & 40 & 16 & 16 & 71 \\
Transport material & 24 & 20 & 18 & 60 \\
Other manufacturing industries & 9 & 11 & 37 & 57 \\
\hline
\end{tabular}

This table presents the number of plants in each manufacturing sector in our sample.

The table breaks each sector into three subsectors, production of capital, intermediate and consumption goods. Note that some plants actually produce more than one type of good.

\section{Empirical Methodology}

The traditional empirical approach in the literature of the determinants of organizational form runs a simple OLS regression using cross-sectional data ${ }^{4}$ such that,

$$
\mathrm{Y}_{\mathrm{it}}=\alpha+\beta \mathrm{X}_{\mathrm{it}}+\mathrm{u}_{\mathrm{it}}
$$

where $Y_{i t}$ is an indicator variable for whether firm i uses a determinate organizational form, $X_{i t}$ is a control variable that includes various determinants of organizational form (according to the theory or theories that are being tested) and $u_{i t}$ is just some random noise where each observation is assumed to be an identically and independently random draw from a normal distribution.

This type of approach faces the main problem that the error term is often correlated with the control variables at use and this ends up creating a bias in the estimation of the coefficient of interest $\beta$. In other words, let us assume that we can break the error term, $\mathrm{u}_{\mathrm{it}}$, into two different terms. The first term, $\theta_{\mathrm{i}}$, is firm-specific and does not vary across time; whereas the second term, $\epsilon_{\mathrm{it}}$, does vary across firms and time and is distributed according to a normal i.i.d. such that

$\mathrm{u}_{\mathrm{it}}=\theta_{\mathrm{i}}+\epsilon_{\mathrm{it}}$

\footnotetext{
${ }^{4}$ See Monteverde and Teece (1982), Masten (1984) or more recently Gil (2007).
} 
Therefore, if it is the fact that $\theta_{\mathrm{i}}$ is correlated with $\mathrm{X}_{\mathrm{it}}$, the first approach will be invalid because standard OLS estimation will yield biased estimates of the coefficient $\beta$ since $u_{i t}$ will be correlated with $\mathrm{X}_{\mathrm{it}}$. The literature has followed different alternative approaches to address this bias. The first approach has advantageously used the time variation available in the data by taking first differences of the dependent and control variables

$$
\Delta \mathrm{Y}_{\mathrm{it}}=\beta \Delta \mathrm{X}_{\mathrm{it}}+\Delta \epsilon_{\mathrm{it}}
$$

When doing this we are taking first differences of the error terms such that

$\Delta \mathrm{u}_{\mathrm{it}}=\mathrm{u}_{\mathrm{it}}-\mathrm{u}_{\mathrm{it}-1}=\theta_{\mathrm{i}}+\epsilon_{\mathrm{it}}-\theta_{\mathrm{i}}-\epsilon_{\mathrm{it}-1}=\epsilon_{\mathrm{it}}-\epsilon_{\mathrm{it}-1}=\Delta \epsilon_{\mathrm{it}}$

and therefore the new error term $\Delta \epsilon_{\text {it }}$ will be uncorrelated with the explanatory variable since we were able to get rid off the unobservable (and correlated with $\mathrm{X}_{\mathrm{it}}$ ) component $\theta_{\mathrm{i}}$.

The second approach would be to instrument for $X_{\text {it }}$ (see Acemoglu et al., 2006). To do so, we would need to find instruments for each one of the possible endogenous variables that are correlated with each one of the respective instrumented variables and yet uncorrelated with the dependent variable and the other instruments. Instead of doing this, our approach is to work hard to minimize the omission variable bias as much as possible. For this reason, we are going to introduce fixed effects at the industry and sector levels such that the determinants of changes in the organization of production are identified from variation within an industry and within a sector and not out of industry-specific and sector-specific shocks that may be driving decisions of all plants in that particular sector or industry. This type of wide-spread shock could be caused by regulation or common technology, demand or supply shocks that are not specifically controlled for in our specification. Nevertheless, we anticipate that some plants within an industry or sector may have faced different shocks or may be characterized by different factors (size, age or labor-intensity) that make them react differently to the same shocks. We introduce all variables available to us in our data set that vary at the plant level and may be correlated with these plant-level shocks that could drive outsourcing decisions. We show the results of our methodology in the next section, keeping in mind that eventually we are posing an empirical question and, therefore, we are aiming to unravel which factors are the most important determinants of the boundaries of the firm and the changes in the organization of production among all possible alternatives.

\section{Results}

In this section we show the results of applying the methodology described in the previous section. We divide the evidence presented here in two main branches of evidence. The first part directly addresses the question of what are the determinants of the changes in the organization of production conditional on the information available to us. The second part will try to explore alternative explanations and robustness for our initial results. 


\section{Initial Set of Results}

We develop our first set of results in Tables 3, 4 and 5. We start by showing results from Table 3 by running the regression equation (2) specified above in our methodology section. Table 3 shows raw correlations between changes in outsourcing and changes in the environment such as prices, competition and market quota among others. These results show that there is a positive and significant correlation between increases in the use of outsourcing and increases in the number of employees, increases in production costs, increases in product quality, increases in product prices, increases in competition and increases in market quota. These correlations are individual correlations between changes in outsourcing and changes in each one of these variables without controlling for anything else. We cannot learn much about the determinants of changes in outsourcing practices from this table since each one of these could be spurious correlations and meaningless from an economics point of view.

\section{Table 3}

Direct correlation between the change in outsourcing practices and other changes in the firm

(1) 0.0894
$(0.0272)^{* \star *}$

Change in production costs?

Change in product quality?

Change in product price?

Change in competition?

Change in market quota?

Constant

Observations

R-squared
(2)

(3)

(4)

(5)

(6)

$$
(0.0272)^{*+*+}
$$

0.0888

$(0.0309)^{\star \star *}$

Robust standard errors in parentheses. ${ }^{*}$ significant at $10 \% ;{ }^{* *}$ significant at $5 \% ;{ }^{* * *}$ significant at $1 \%$.

For this reason, in Table 4, we start running regression equation (2) controlling for one additional explanatory variable at a time. The results appear in column (1) through (5) in that table. We can then learn about some of the spuriousness of the correlations shown in Table 3 since some of these explanatory variables lose significance as we include other explanatory variables in the analysis. At the end, in column (5) only the statistical significance of the increases in the costs of production and the market quota survive the inclusion of other variables in the regression equation. The result in column (5) may be indicating that plants that saw increases in their costs of production and their market quota also saw in some instances increases in their product prices, product quality and competition, but their increases in outsourcing were correlated directly with increases in production costs and increases in market quota, and indirectly with all the other variables. 


\section{Table 4}

The determinants of the change in outsourcing practices in a firm

\begin{tabular}{|c|c|c|c|c|c|c|c|}
\hline & (1) & (2) & (3) & (4) & (5) & (6) & (7) \\
\hline Change in \# employees? & $\begin{array}{l}0.0692 \\
(0.0291)^{\star \star}\end{array}$ & $\begin{array}{l}0.0660 \\
(0.0294)^{* *}\end{array}$ & $\begin{array}{l}0.0523 \\
(0.0294)^{\star}\end{array}$ & $\begin{array}{l}0.0491 \\
(0.0294)^{*}\end{array}$ & $\begin{array}{c}0.0016 \\
(0.0311)\end{array}$ & $\begin{array}{c}-0.0005 \\
(0.0309)\end{array}$ & $\begin{array}{c}-0.0070 \\
(0.0322)\end{array}$ \\
\hline Change in production costs? & $\begin{array}{l}0.0662 \\
(0.0327)^{* *}\end{array}$ & $\begin{array}{l}0.0623 \\
(0.0328)^{*}\end{array}$ & $\begin{array}{l}0.0554 \\
(0.0332)^{*}\end{array}$ & $\begin{array}{l}0.0513 \\
(0.0330)\end{array}$ & $\begin{array}{l}0.0569 \\
(0.0329)^{*}\end{array}$ & $\begin{array}{l}0.0587 \\
(0.0326)^{*}\end{array}$ & $\begin{array}{l}0.0584 \\
(0.0336)^{*}\end{array}$ \\
\hline Change in product quality? & & $\begin{array}{l}0.0529 \\
(0.0477)\end{array}$ & $\begin{array}{l}0.0476 \\
(0.0479)\end{array}$ & $\begin{array}{l}0.0510 \\
(0.0482)\end{array}$ & $\begin{array}{c}0.0022 \\
(0.0475)\end{array}$ & $\begin{array}{l}0.0017 \\
(0.0466)\end{array}$ & $\begin{array}{c}-0.0044 \\
(0.0475)\end{array}$ \\
\hline Change in product price? & & & $\begin{array}{l}0.0786 \\
(0.0330)^{* *}\end{array}$ & $\begin{array}{l}0.0765 \\
(0.0330)^{* *}\end{array}$ & $\begin{array}{l}0.0585 \\
(0.0337)^{\star}\end{array}$ & $\begin{array}{l}0.0534 \\
(0.0343)\end{array}$ & $\begin{array}{l}0.0430 \\
(0.0354)\end{array}$ \\
\hline $\begin{array}{l}\text { Change in competition? } \\
\text { Change in market quota? }\end{array}$ & & & & $\begin{array}{l}0.0723 \\
(0.0419)^{*}\end{array}$ & $\begin{array}{l}0.0561 \\
(0.0406) \\
0.2233\end{array}$ & $\begin{array}{l}0.0579 \\
(0.0414) \\
0.2179\end{array}$ & $\begin{array}{l}0.0516 \\
(0.0429) \\
0.2120\end{array}$ \\
\hline Constant & $\begin{array}{c}0.2157 \\
(0.0282)^{* \star *}\end{array}$ & $\begin{array}{c}0.1809 \\
(0.0415)^{\star \star \star}\end{array}$ & $\begin{array}{c}0.1559 \\
(0.0435)^{* * *}\end{array}$ & $\begin{array}{l}0.1148 \\
(0.0489)^{* *}\end{array}$ & $\begin{array}{c}(0.0400)^{* \star *} \\
0.0817 \\
(0.0495)^{*}\end{array}$ & $\begin{array}{c}(0.0399)^{\star * *} \\
0.0287 \\
(0.1247)\end{array}$ & $\begin{array}{l}(0.0415)^{* \star \star} \\
-0.6834 \\
(0.3276)^{* *}\end{array}$ \\
\hline Fixed Effects & No & No & No & No & No & Sector & $\begin{array}{l}\text { Intermediate } \\
\text { Sector }\end{array}$ \\
\hline $\begin{array}{l}\text { Observations } \\
\text { R-squared }\end{array}$ & $\begin{array}{l}903 \\
0.02\end{array}$ & $\begin{array}{l}900 \\
0.02\end{array}$ & $\begin{array}{l}885 \\
0.02\end{array}$ & $\begin{array}{l}876 \\
0.03\end{array}$ & $\begin{array}{l}817 \\
0.07\end{array}$ & $\begin{array}{l}817 \\
0.09\end{array}$ & $\begin{array}{l}811 \\
0.11\end{array}$ \\
\hline
\end{tabular}

Robust standard errors in parentheses. ${ }^{*}$ significant at $10 \% ;{ }^{* *}$ significant at $5 \% ;{ }^{* * *}$ significant at $1 \%$.

To conclude with Table 4, in column (6) we introduce first fixed effects at the industry level and in column (7) we introduce fixed effects at the industry-sector level. ${ }^{5}$ By doing this, we check that the results in column (5) are not subject to any industry or industry-sector specific shock. Therefore our finding is consistent across firms within and across industries and sectors. Table 4 then provides our first finding; that increases in outsourcing are positively correlated with increases in production costs and increases in market quotas. These findings are not surprising since they just indicate that firms will outsource more of their production when their costs increase and therefore they are forced to look for cheaper alternatives in the marketplace. Similarly, as their market quota increases, the plants may not be able to temporarily adjust their production capacity (or it may be too costly to do so) and therefore they will rely on outsourcing as a temporary solution.

Finally in Table 5 we explore the underlying correlations between the explanatory variables used through Table 3 and 4 and the dependent variable changes in outsourcing. For this purpose, we will use interactions between the explanatory variables and therefore potentially discover that some of the explanatory variables that we thought to be innocuous display some degree of heterogeneity in their effect that is correlated with changes in other variables of our analysis.

\footnotetext{
${ }^{5}$ Industry fixed effects would be fixed effects for each of the 12 categories in the vertical columns in Table 2 , whereas industry-sector fixed effects would be the result of interacting those 12 categories with whether the firm produces capital, intermediate or consumer goods.
} 


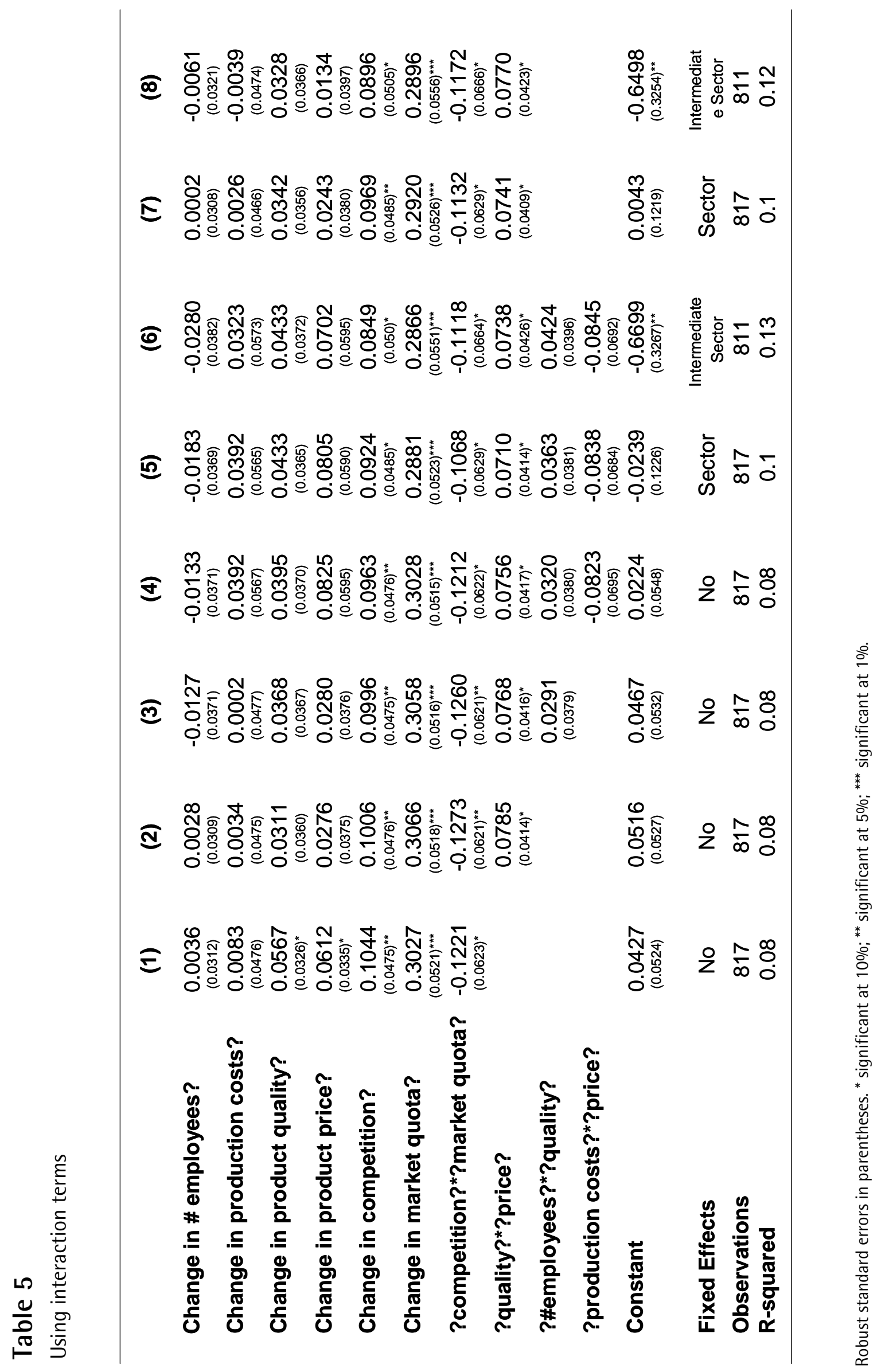


We start Table 5 by including the interaction between market quota and competition in the regression equation displayed in column (5) of Table 4. A number of changes occur when we do this. First, the positive correlation between increases in outsourcing and increases in production costs disappears. Second, the positive correlations between increases in outsourcing and increases in product quality and product prices become statistically significant. Third and last, and in our opinion most important, the correlation between increases in competition and increases in outsourcing becomes positive and statistically significant whereas the coefficient of the interaction between competition and market quota is negative, statistically significant and of a similar magnitude (absolute value) of the coefficient in the variable changes in competition. The coefficient of the variable increases in market quota stays positive and statistically significant. This set of results indicates that, while increases in competition raise the amount of outsourcing used by plants in our sample, those plants that see their market quota increase at the same time are less likely to increase outsourcing, and they may even decrease the total amount of outsourcing. This result will be robust to the inclusion of other interaction variables and fixed effects at the industry and sector level through column (8) in Table 5.

In column (2) we introduce the interaction between changes in product quality and changes in product prices to the regression equation run in column (1). We can emphasize a few facts from the findings in column (1). First, the coefficient of changes in production costs remains statistically insignificant. Second, the statistical significance of the coefficients on the changes in product quality and product prices disappears. Third, as indicated previously, the statistically significant correlations between competition and the first interaction variable remain significant and keep the same sign. Fourth, the newly introduced interaction variable has a positive and statistically significant coefficient. This set of new results mainly indicates that, even though facing increases in product quality or increases in product prices alone does not change outsourcing decisions by the plants in our sample, plants that face both increases in product quality and increases in product prices at the same time do increase the use of outsourcing. An explanation that could reconcile this set of correlations is the following: only in those situations when a plant faces an increase in product quality that requires a simultaneous increase in prices would the plant actually increase their use of outsourcing practices. These could be increases in product quality that will either increase prices because the product could target different clientele or increase production costs (even though this is already controlled for in our specification).

In columns (3) and (4) we include two different interactions: an interaction between the increase in number of workers and the increase in quality, and an interaction between the increase in production costs and the increase in product prices respectively. The inclusion of these two interaction variables do not change the results obtained in column (2) and therefore seem to indicate that changes in product prices that are correlated with changes in production costs are not correlated with changes in outsourcing. Similarly, changes in product quality correlated with changes in the number of employees in the plant are not correlated with changes in outsourcing. Both these results are useful in determining the nature of changes experienced in both product quality and product prices. They point out that changes in quality and prices that are due to internal changes within the plant have no relation with outsourcing decisions and therefore they can, for our purposes, be thought as of exogenous.

Next we introduce fixed effects at the industry and sector level in columns (5) and (6). Results are robust to the introduction of these. Finally, in columns (7) and (8), we consciously choose the specification in column (2) as the regression equation to be used throughout the paper from this point on. Therefore, we check whether the results obtained there are robust to the inclusion 
of industry and sector fixed effects while leaving out the third and fourth interactions introduced in columns (3) and (4). Our results here are robust as well and therefore we proceed from now on with this particular specification when we undertake a few robustness checks.

Before proceeding with various robustness checks below, let us summarize our findings so far. Our most robust results show that increases in competition are positively and statistically significant correlated with increases in outsourcing, but this correlation reverses when the increase in competition is accompanied by an increase in market quota. We also find that increases in market quota alone are correlated with increases in outsourcing. Finally, for our sample of Spanish plants we have also learned that, even though increases in product prices and increases in product quality alone have no impact on outsourcing practices, increases in product quality that come together with increases in product prices are positively correlated with increases in outsourcing.

\section{Alternative Explanations}

The first robustness check that we undertake in this paper concerning the results in Tables 3,4 and 5 is about the nature of the reorganization of production that takes place in the manufacturing sector during this period. The unit of observation in our data set is the manufacturing plant. This level of observation introduces the complication that some of the observations belong to one-plant firms and others to multi-plant firms. The organization of production that takes place in either of these organizational units may be very different even when the answer to whether outsourcing has grown is the same. Plants belonging to multi-plant firms may be experiencing a reorganization of services and tasks across plants within the firm, whereas we are certain that plants that are firms themselves (one-plant firms) are reorganizing activities across their boundaries when claiming a change in outsourcing practices.

For this purpose, in Table 6 we separately examine the behavior of plants belonging to oneplant firms and multi-plant firms following the specification in column (2) of Table 5. The first three columns in Table (6) show the results of Table 5's columns (2), (7) and (8) for expositional purposes, and so that the new results are easier to compare with those obtained before. Then columns (4) to (6) in Table 6 show results for one-plant firms only and columns (7) to (9) show results for multi-plant firms only. According to this division, we have 432 one-plant firms in our sample and 385 plants that belong to multi-plant firms. Results from Table 6 show that plants belonging to different types of organizations react differently to changes in product prices, product quality, competition and market quota. 


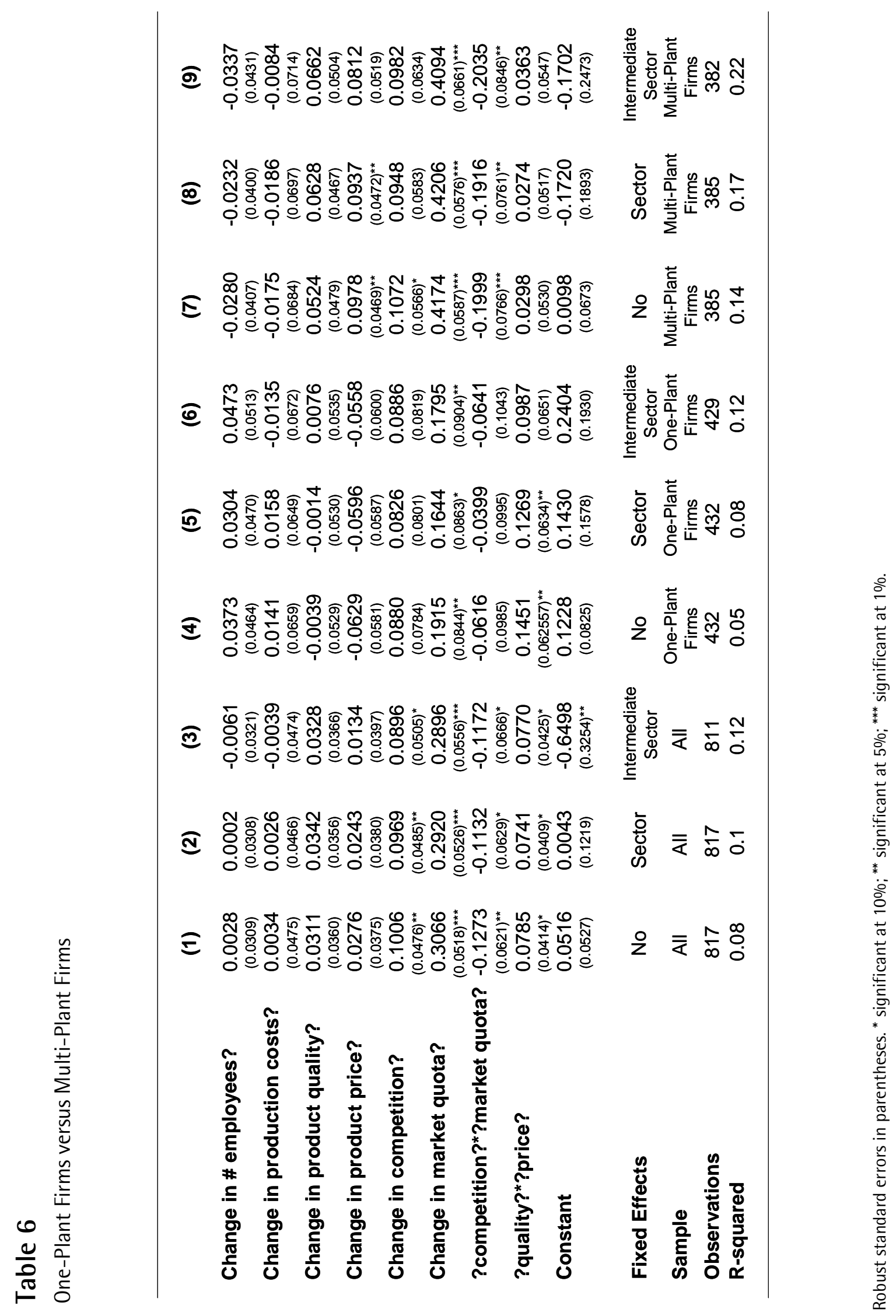


On the one hand, one-plant firms (basically stand-alone plants) increase outsourcing with increases in market quota and simultaneous increases of product quality and product prices, but they seem to be unaffected by changes in competition. On the other hand, plants belonging to multi-plant firms increase outsourcing when facing increases in product prices, increases in competition and increases in market quota, but they decrease outsourcing when facing simultaneous increases in competition and market quota. They seem to be unaltered, according to our results here, to simultaneous changes in product prices and product quality. These differences in determinants of changes in outsourcing shed light on how different firms may reorganize their production differently when facing different types of shocks. Our evidence here seems to indicate that stand-alone plants fail to reorganize when facing an increase in competition, whereas multi-plant firms seem to reorganize much easier through outsourcing (outside the plant, not the firm) when facing an increase in competition. This may be because outsourcing for stand-alone plants may mean relying on their own competitors for input supplies or relying on suppliers that also supply their competitors. Multi-plant firms may be able to reorganize their resources within the firm and across plants and therefore be able to rely less on their competitors, either directly or indirectly. Yet both types of firms seem to increase outsourcing with increases in market quota and competition (not always statistically significant) and decrease outsourcing when facing simultaneous increases in competition and market quota.

The other potential problem that our analysis in Table 5 may encounter is one of variable omission or endogeneity. If this were the case, even after including sector fixed effects, the difference in error terms may actually correlate with our explanatory variables (and their interactions). This could potentially bias our results to the point of flipping signs of coefficients from negative to positive or vice versa, or even making some variables statistically insignificant even though they have explanatory value for the observed patterns of changes in outsourcing practices.

To address this issue, we basically use all relevant variables available in our data set that describe dimensions of the plants that a priori may be correlated with differences in levels of outsourcing adopted by the firms, and hope that those are also correlated with changes in outsourcing. ${ }^{6}$ Therefore in Table 7 we introduce variables such as the percentage of labor costs for the plant, a dummy variable for whether the plant had adopted new technologies within the previous year, the average number of employees during 2005 and the year in which the plant started working as a proxy for the age of the plant. We introduce all these variables to attenuate the omission variable bias and, to some extent, the remaining potential endogeneity problem after differentiating the dependent and explanatory variables, as well as introducing fixed effects at the industry and sector level. Results columns (1) to (15) show that the inclusion of these variables has no impact on the results obtained in previous tables. As a reminder, it is still true that increases in competition and market quotas alone increase outsourcing, but combined increases in competition with increases in market quotas decrease outsourcing. Finally, it is still also the case that increases in product quality combined with increases in product prices are positively correlated (and statistically significant) with increases in outsourcing practices.

\footnotetext{
${ }^{6}$ Although this may seem far from a true and general statement, we do think that plants that do not outsource at all will be more likely to experience increases in outsourcing, and plants that outsource a lot of their activity will be more likely to cut on their outsourcing practices.
} 


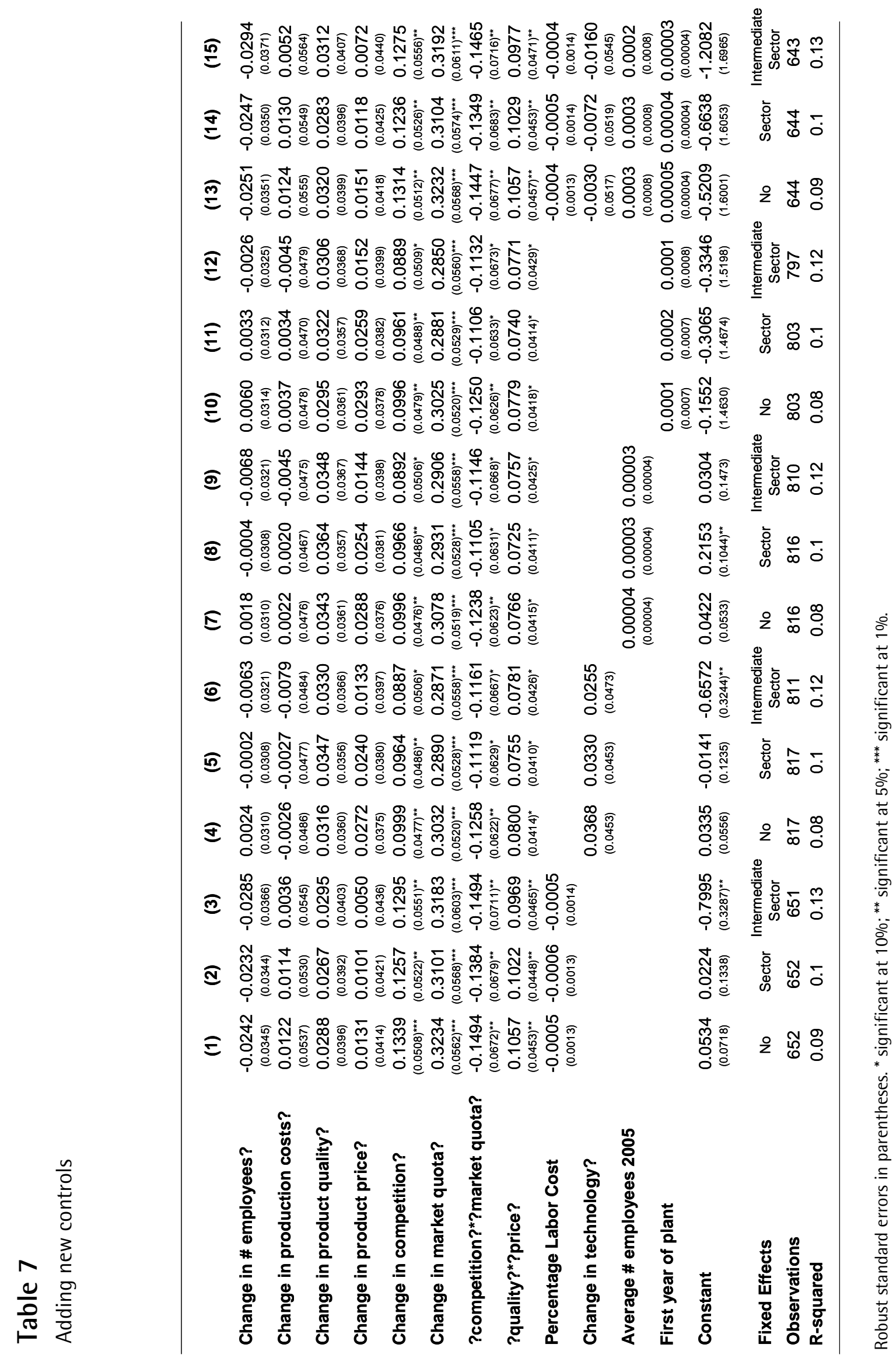




\section{Discussion of Results}

The empirical findings portrayed here are consistent with a few well-established theories of vertical integration and specialization, as well as recent theoretical results. As a starter, the finding that plants rely on outsourcing more when they obtain a larger market quota is consistent with Adam Smith's claim that the degree of specialization (more specialization more outsourcing) is limited by the extent of the market. Our findings show that, as firms can exploit economies of scale, the gains of specialization and outsourcing also grow.

Our results are also consistent with predictions from the Transaction Cost Economics literature in that, when a firm faces more competition, the degree of vertical integration (outsourcing) decreases (increases). This is so because, with increases in competition, the value of relationship-specific assets increases and the value of quasi-rents goes down. Therefore the need to vertically integrate to prevent hold-up diminishes. In this same regard, most recent theoretical papers that have relied on property rights theories to shed light on the role of competition in make-or-buy decisions have also argued that there is a positive relationship between competition and outsourcing (see, for example, De Bettignies, 2007). However, others such as Grossman and Helpman (2002) have offered different case scenarios in which it could go either way. Therefore, this becomes an empirical question for which we provide an answer within our sample of Spanish manufacturing plants. Our result that simultaneous increases between competition and market quotas may decrease outsourcing and therefore increase vertical integration is at odds with this theoretical literature and we hope it will foster future research.

As part of our robustness checks, we also examine the role of technology in outsourcing decisions and, contrary to Acemoglu et al. (2006), we do not find evidence that this has any role for outsourcing decisions within our framework and sample. We are aware that theirs is a more detailed and comprehensive data set but we find no support for their claims within our empirical setting.

On the other hand, our results only partially support evidence of findings in Hortaçsu and Syverson (2008). First, contrary to them, we find that increases in market quota or plant size are positively related to outsourcing. Second, and consistent with them, we find that one-plant versus multi-plant firms show different outsourcing patterns and adjust their make-or-buy decisions reacting differently to different changes in their market environment.

Finally, our result that simultaneous increases in product quality and product prices are correlated with increases in outsourcing is also at odds with standard arguments of Property Rights and Transaction Costs theories of vertical integration. These theories predicate that increases in product quality will be accompanied by specific investments of some type or increases in the likelihood of suppliers' opportunistic behavior and therefore these will derive into increases in vertical integration. Here we find the opposite result. Therefore this result constitutes more supporting evidence for Adam Smith's theory of vertical integration (or specialization). As product price and product quality increase simultaneously, market 'thickness' or saturation of potential suppliers may also increase and it may therefore be easier to find a good supplier that will perform the outsourced task in a timely and efficient manner at a reasonable cost. 


\section{Conclusions}

In this paper we have explored how plants within the Spanish manufacturing industry have changed their outsourcing practices due to changes in their competitive environment. This empirical exercise sheds light then on the make-or-buy decisions in a comprehensive manner, since plants in our sample are spread across 12 manufacturing industries. Thus, the analysis here departs from the industry-specific studies that have been flooding the empirical literature in vertical integration.

Our findings show that plants in our sample increase their levels of outsourcing when they face increases in both market competition and their market quota. Surprisingly, we find robust evidence that simultaneous increases in competition and market quota will decrease outsourcing, and also that simultaneous increase in product quality and product prices will increase outsourcing. Some of these results are consistent with both TCE and PRT predictions in patterns of vertical integration but others are not. Eventually the simple explanation provided by Adam Smith in that the degree of specialization is limited by the extent of the market seems to be the most reconciling explanation for all the patterns that we observe in our paper. 


\section{References}

Acemoglu, D., P. Aghion, R. Griffin and F. Zilibotti (2006), "Vertical Integration and Technology: Theory and Evidence,” NBER Working Paper No. 10037.

Alchian, A. and H. Demsetz (1972), "Production, Information Costs, and Economic Organization," American Economic Review, Vol. 62, pp. 777-795.

Coase, R. (1937), “The Nature of the Firm,” Economica vol. 4(16), pp. 386-405.

De Bettignies, J. (2006), "Product Market Competition and the Boundaries of the Firm," Canadian Journal of Economics, vol. 39(3), pp. 948-970.

Forbes, S. and M. Lederman (2008), "Adaptation and Vertical Integration in the Airline Industry," forthcoming in American Economic Review.

Gil, R. (2007), "Make-or-Buy," in "Movies: Integration and Ex-post Renegotiation," International Journal of Industrial Organization, vol. 25(4), pp. 643-656.

Gil, R. (2008), "Revenue Sharing Distortions and Vertical Integration in the Movie Industry," forthcoming Journal of Law, Economics and Organization.

Gil, R. and W. Hartmann (2008), “Airing Your Dirty Laundry: Vertical Integration, Reputational Capital and Social Networks," manuscript.

Grossman, S. and 0. Hart (1986), "The Costs and Benefits of Ownership: A Theory of Vertical and Lateral Integration," Journal of Political Economy, vol. 94 (August), pp. 691-719.

Grossman, G. M. and E. Helpman (2002), "Integration Versus Outsourcing in Industry Equilibrium," Quarterly Journal of Economics, vol. 117(1), pp. 121-148.

Hortaçsu, A. and C. Syverson (2008), "Vertical Integration and Production: Some Plant-Level Evidence," Working Paper, 2008.

Klein, B., R. Crawford, and A. Alchian (1978), "Vertical Integration, Appropriable Rents, and the Competitive Contracting Process," Journal of Law and Economics, vol. 21, pp. 297-326.

Lafontaine, F. and M. Slade (2007), "Vertical Integration and Firm Boundaries: The Evidence," Journal of Economic Literature, vol. 45(3), pp. 629-685.

Masten, S. (1984), "The Organization of Production: Evidence from the Aerospace Industry," Journal of Law \& Economics, vol. 27(2), pp. 403-417.

Monteverde, K. and D. Teece (1982), "Appropriable Rents and Quasi-Vertical Integration," Journal of Law and Economics, vol. 25(2), pp. 321-328.

Legros, P. and A. Newman (2008), “Competitive Prices and Organizational Choices,” manuscript. Whinston, M. (2003), “On the Transaction-Cost Determinants of Vertical Integration,” Journal of Law, Economics, and Organization, vol. 19(1), pp. 1-23.

Williamson, 0. (1975), Markets and Hierarchies, New York, The Free Press.

Williamson, 0. (1979), "Transaction-Cost Economics: The Governance of Contractual Relationships," Journal of Law and Economics, vol. 22, pp. 232-262. 